\title{
TEORIA CRÍTICA E PSICOLOGIA SOCIAL: RELEVÂNCIA DAS PESQUISAS EMPÍRICAS
}

\author{
TEORÍA CRÍTICA Y PSICOLOGÍA SOCIAL: RELEVANCIA DE LAS \\ INVESTIGACIONES EMPÍRICAS \\ CRITICAL THEORY AND SOCIAL PSYCHOLOGY: RELEVANCE OF \\ EMPIRICAL RESEARCH \\ http://dx.doi.org/10.1590/1807-0310/2018v30174315 \\ José Leon Crochick ${ }^{1}$ \\ ${ }^{1}$ Universidade de São Paulo, São Paulo/SP, Brasil
}

\begin{abstract}
RESUMO
O objetivo deste ensaio é indicar limites e avanços obtidos pela psicologia social, tal como é delimitada pela Teoria Crítica da Sociedade, sobretudo por Theodor. W. Adorno, por meio de estudos empíricos desenvolvidos desde a década de 1990, em nosso meio. Para o cumprimento desse objetivo, foi dividido em três partes; na primeira delas, discute-se acerca da disciplina psicologia social, sob a ótica da Teoria Crítica da Sociedade; na segunda parte, dá-se ênfase à importância da pesquisa empírica para a Teoria Crítica; por fim, na última parte, são apresentados alguns resultados das pesquisas acima referidas, indicando confirmação ou não de resultados anteriores, obtidos pelos autores da Teoria Crítica da Sociedade, e o aporte empírico que esses dados trazem para essa Teoria.
\end{abstract}

Palavras-chave: psicologia social; teoria crítica da sociedade; pesquisa empírica.

\section{RESUMEN}

El propósito de este ensayo es indicar límites y avances de la psicología social, tal como se define por la teoría crítica de la sociedad, especialmente por T. W. Adorno, a través de estudios empíricos realizados desde la década de 1990. Para ello, este trabajo se divide en tres partes: la primera discute la disciplina psicología social desde la perspectiva de la Teoría Crítica; la segunda parte hace hincapié en la importancia de la investigación empírica para esa teoría; finalmente, la última parte presenta algunos resultados de investigaciones anteriores, indicando la confirmación o no de los resultados previos obtenidos por los autores de la teoría crítica de la sociedad, y la contribución empírica que estos datos traen a esta teoría.

Palabras clave: psicología social; teoría crítica de la sociedad; investigación empírica.

\begin{abstract}
The objective of this essay is to indicate limits and advances obtained by social psychology, as it is delimited by the Critical Theory of Society, especially by T.W. Adorno, through some empirical studies developed since the 1990s in our country. To achieve this goal, the essay was divided in three parts. In the first one, we discuss about the discipline of social psychology, from the Critical Theory of Society viewpoint. In the second part, the importance of the empirical research for the Critical Theory is emphasized. Finally, in the last part, some results of the mentioned above researches are presented, indicating confirmation or not of previous results obtained by the authors of the Critical Theory of the Society and the empirical contribution that these data bring to this Theory.
\end{abstract}

Keywords: social psychology; critical theory of society; empirical research. 


\section{Introdução}

Este ensaio está dividido em três partes que intentam pensar a importância da pesquisa empírica para a psicologia social, tal como a delimitam autores da Teoria Crítica da Sociedade, principalmente Max Horkheimer e Theodor W. Adorno. Para isso, discutese: a delimitação da disciplina de psicologia social para esses autores; os limites e a relevância de pesquisas para, junto com a teoria, elucidar temas que permitam compreender, sobretudo, a violência contemporânea e a possibilidade de evitá-la ou, ao menos, resistir a ela; e dados de pesquisas brasileiras, surgidas a partir dos estudos dos frankfurtianos, que permitam consolidar o que já foi estabelecido e/ou novas informações que indiquem novas direções.

\section{Psicologia social da perspectiva da Teoria Crítica da sociedade}

Em um de seus cursos - lições de sociologia Adorno (1968/2008) considera a psicologia social como parte da sociologia e não da psicologia; seria responsável para compreender o amálgama que une as pessoas na sociedade. Em seu ensaio "De la relación entre sociología e psicologia", Adorno (1955/1991b), ainda que ciente da restrição de Freud à expressão composta "psicologia social", julga necessário diferenciá-la do que seria próprio ao estudo da mônada psicológica.

Essa distinção entre psicologia e psicologia social revela um objeto cindido entre sua própria constituição e a tendência de sua regressão. A atuação social talvez retrate a tendência ao fingimento: a máscara social que temos de usar para viver em coletividade; pode ser que indique a regressão do indivíduo, assinalada por Freud (1921/1993), quando esse age em grupo; mas é essa regressão psíquica, que ocorre quando o indivíduo está em grupo, que pode indicar a fragilidade do ideal de eu, que, por sua vez, para Freud pode levar à situação de pânico, quando o ideal coletivo colocado no lugar do ideal individual é posto em questão, e, nesse caso, não se trata de mera aparência social, mas um sinal do que ocorre com o próprio objeto que representa.

Para Adorno (1955/1991b), no entanto, seria próprio da psicologia o estudo da mônada, e para a psicologia social, os comportamentos padronizados, massificados; essa distinção, no entanto, conforme enfatizado, pode levar à desconsideração do próprio objeto que não desaparece na multidão. Com tal distinção entre psicologia e psicologia social, há dificuldades de explicar a asserção que esse autor faz sobre as regressões psíquicas necessárias para a reprodução social, ou a que profere em conjunto com Horkheimer (Horkheimer \& Adorno, 1956/1973), indicando que a ideologia visa a disposições psíquicas para que o indivíduo apoie uma mentira manifesta. Nesses casos, o indivíduo é constituído socialmente, e não há como entendê-lo somente da perspectiva psíquica, como uma mônada, pois, como o mesmo autor insiste em afirmar, o indivíduo é mediado socialmente. Os trabalhos sobre a personalidade autoritária e o fragmento "Elementos do antissemitismo" (Horkheimer \& Adorno, 1947/1985) atestam essa regressão psíquica resultante da repressão social. Diferenciar psicologia de psicologia social, nesse sentido, não ajuda a entender o objeto desta última, que, a rigor, não deve se diferençar da primeira. Com a dificuldade cada vez maior do indivíduo se constituir, se Freud pode assinalar que toda psicologia tende a ser psicologia social, atualmente, pode-se argumentar que toda psicologia social é psicologia, quando essa é delimitada pelo estudo do que é irracional, ainda que contido por uma pretensa e superficial racionalidade, o que indica a frágil constituição atual do eu, como aponta Adorno (1955/1991b).

No pós-escrito de De la relación entre sociología e psicología, Adorno (1966/2015), com posição algo distinta da acima destacada, ressalta:

Não se deve hipostasiar, de fato, nenhuma consciência ou inconsciente coletivos; além disso, os conflitos se desenrolam, por assim dizer, sem janelas nos indivíduos e devem ser deduzidos nominalisticamente de sua economia pulsional individual - mas eles possuem forma idêntica em inumeráveis indivíduos. Por isso, o conceito de psicologia social não é tão equivocado quanto esta palavra composta e seu uso mundialmente disseminado fazem crer. (p. 129)

Nesse trecho, Adorno está indicando a regressão psíquica que torna a psicanálise anacrônica e, por isso, a necessidade de uma psicologia social analiticamente orientada para compreender aquela regressão, própria do fascismo, desde que também com o emprego conjunto da teoria da sociedade, mas não mais somente a psicologia ou a psicanálise. Em outros termos, ao se considerar que o objeto da psicologia/ psicanálise se modificou, a disciplina que o estuda não pode permanecer igual. $\mathrm{O}$ acento sobre o social indica o predomínio cada vez maior da sociedade sobre o indivíduo, que pouco pode se diferençar. Mesmo o narcisista, resignado a uma psicologia individual, de acordo com Freud (1921/1993), significa, de acordo com Adorno (1955/1991b), o abandono da consciência e, portanto, já é mediado socialmente. Aliás, o narcisismo não somente é suscitado socialmente pelas 
frustrações aos desejos individuais, como também, quando é combatido, volta-se, segundo Adorno (1969), para objetos sociais, entre os quais o nacionalismo; assim, foi importante para a adesão ao fascismo:

Sería necesario tomar en serio las normas de la vida privada burguesa y darles valor de sociales. Pero un intento tan bienintencionado pasa por alto la imposibilidad de lograrlo, mientras reinen condiciones que, al imponer a los individuos tales renuncias, defraudan en forma tan permanente su narcisismo, los condenan en tal medida a la impotencia, que están condenados a recaer en el narcisismo colectivo. A modo de sucedáneo, el nacionalismo les devuelve, como individuos, parte del propio respeto que la colectividad les sustrae y cuya recuperación esperan de ella, al identificarse ilusoriamente con la misma. (Adorno, 1969, p. 154)

Além dos fenômenos de massa, como enfatizamos anteriormente, a relação das disposições individuais com as necessidades sociais nitidamente é destacada acima, assim, uma psicologia social não deve somente descrever e entender a adaptação dos indivíduos à sociedade, mas estudar as disposições incutidas nesses indivíduos necessárias à reprodução social.

Em síntese, parece que, atualmente, o termo psicologia social analiticamente orientado não convive com uma psicanálise ou com uma psicologia, mas as substitui, e seu objeto deve ser um ego, refém de pressões sociais e de desejos e expectativas individuais, para o qual deve se voltar.

Se o indivíduo é um organismo que se desenvolve mediado por um sistema - a sociedade -, não cabe mesmo diferençar natureza de cultura ou de sociedade, mas o termo composto - psicologia social - pode indicar, como supomos, a cada vez menor diferenciação individual que não é a priori da formação, mas um desenvolvimento que ocorre paulatinamente. Não há um indivíduo, de um lado, e uma sociedade de outro, mas só há indivíduo se a sociedade permitir que se desenvolva, se diferencie. Nesse sentido, compreender que os frankfurtianos são freudo-marxistas pode levar ao equívoco de se tratar de uma relação de objetos equivalentes, quando a determinação recíproca não é simétrica e nem de igual intensidade. Deve-se insistir: não se trata de uma relação $a$ priori entre indivíduo e sociedade, mas de um indivíduo que possa se desenvolver por meio do que a cultura lhe pode oferecer.

\section{Teoria e empiria}

A teoria como compreensão do movimento de um objeto ao qual deve sua existência deve se alterar em conformidade com esse objeto, por isso, nunca pode ser posta à prova ou ser falseável; caso considere seu objeto sem movimento, não é teoria, mas descrição de um momento estático, que tem seu valor, desde que colocado novamente em movimento. Se todos objetos são mediados socialmente, a história de cada objeto é simultaneamente a história da sociedade; sociedade que se expressa de diversas formas pelos distintos objetos.

Nesse sentido, as análises de Horkheimer e Adorno (1947/1985) são fiéis ao pensamento marxista; é o que se pode concluir do trecho abaixo do prefácio da Dialética do Esclarecimento:

Nas condições atuais, os próprios bens da fortuna convertem-se em elementos do infortúnio. Enquanto no período passado, a massa desses bens, na falta de um sujeito social, resultava na chamada superprodução, em meio às crises da economia interna, hoje ela produz, com a entronização dos grupos que detêm o poder no lugar desse sujeito social, a ameaça internacional do fascismo: o progresso converte-se em regressão. (p. 15)

Salvo engano, o trecho acima se refere à mudança da determinação fundamental da sociedade: da esfera da economia para a esfera política; nessa alteração, a economia se torna um aporte ideológico. Se Marx (1844/1978) pode indicar que a história é a única ciência, Horkheimer e Adorno indicam sua continuidade e transformação, o que é atestado no prefácio da segunda edição do mesmo livro, publicado um quarto de século após a primeira edição, na qual indicam que a verdade tem um núcleo temporal. Ora, dizer que a verdade tem esse núcleo temporal não implica necessariamente que se reduza a esse núcleo, pois há limites na materialidade a ser modificada e há também continuidade na modificação dos objetos, o que atesta que algo próprio a eles é alterado, realizando suas potencialidades, que lhes são imanentes: essas potencialidades podem se realizar ou não dependendo também de condições sociais, mas são suscitadas pela sociedade, não pertencem a essa. Tome-se como ilustração o conceito psicanalítico de pulsão (Laplanche \& Pontalis, 1988); ela se delimita como representação psíquica de necessidade somática; nesse conceito, nota-se a não dissociabilidade entre corpo e psique, o que não implica que um se confunda com o outro. As necessidades materiais se convertem em desejos, devido aos objetos culturais oferecidos a elas:

La necesidad es una categoría social. La naturaleza, la "pulsión" está contenida dentro de ella. Pero los momentos social y natural de la necesidad no se puede separar entre sí en secundario y primario, para elaborar de este modo una jerarquía de las satisfacciones... Toda pulsión está tan socialmente mediada que su componente natural no aparece 
nunca de forma inmediata, sino siempre como algo producido por la sociedad. La invocación de la naturaleza frente a cualquier necesidad es siempre meramente la máscara de negación y dominio. (Adorno, 1942/2004b, p. 365)

Assim, os limites e as potencialidades dos objetos são desenvolvidos ou não dependendo da mediação social, mas não pertencem a essa. É dessa forma que antes indicamos que o homem é um organismo materialidade - que se desenvolve mediado por um sistema criado pelos homens em sua relação com a natureza - a sociedade. Toda teoria, nesse sentido, tem de se dirigir à história de seu objeto, sem esquecer suas próprias determinações.

O empírico, nesse sentido, referente quer à experiência cotidiana, não restrita à vivência, quer ao experimento científico, permite à teoria prosseguir seu trabalho: o estudo das modificações do objeto que mostram que tem vida; não é mera presa a ser "devorada" para a autoconservação, vai além dessa, de sorte que o conhecimento só poderá ser efetivo - o "em si" e o "para si" do objeto - quando a autoconservação for superada e o conhecimento não tiver de ser destinado unicamente a essa necessidade de sobrevivência: no reino da necessidade, todo esclarecimento se limita à sobrevivência e a vida à mera reprodução; é nesse sentido que Horkheimer e Adorno (1947/1985) criticam a experiência socialista soviética:

Reconhecer, porém, a presença da dominação dentro do próprio pensamento como natureza não reconciliada seria um meio de afrouxar essa necessidade que o próprio socialismo veio a confirmar precipitadamente como algo de eterno, fazendo assim uma concessão ao common sense reacionário. Ao fazer da necessidade, para todo o sempre, a base e ao depravar o espírito de maneira tipicamente idealista como o ápice, ele se agarrou com excessiva rigidez à herança da filosofia burguesa. Assim, a relação de necessidade com o reino da liberdade permaneceria meramente quantitativa, mecânica, e a natureza colocada como algo inteiramente alheio e estranho, como ocorre com a primeira mitologia - tornar-se-ia totalitária e absorveria a liberdade juntamente com o socialismo. (p. 51)

Isso implica que à teoria cabe também indicar os limites que a sociedade existente dá à transformação dos homens - seu objeto por excelência -; é neste sentido que é crítica: mostra os limites sociais ao desenvolvimento humano e clama por sua superação; disso decorrem as relevantes delimitações de liberdade e emancipação. A crítica, por isso, é sempre diretamente feita à sociedade, e não aos indivíduos e às instituições que se constituem por sua intermediação.
A abertura para a experiência - seja essa buscada na tradição ou em novas relações -, defendida por Adorno (1970/1995a) em seus textos sobre educação, permite romper os limites do esclarecimento que quer tudo conhecido de antemão; as pesquisas científicas permitem por meios técnicos realizar a "fantasia exata" preconizada por esse autor. O fato de a fantasia e a imaginação poderem pensar os dados por meio de diversas combinações possibilita perceber seu movimento, que não é restrito ao que é apreendido pelo método:

Una fantasía exacta; fantasía que se atiene estrictamente al material que las ciencias le ofrecen, y sólo va más allá en los rasgos mínimos de la estructuración que ella establece: rasgos que ciertamente ha de ofrecer de primera mano y a partir de sí misma. Si es que la idea de interpretación filosófica que me había propuesto exponer ante ustedes tiene alguna vigencia, se pueda expresar como la exigencia de dar cuenta en todo momento de las cuestiones de la realidad con que tropieza, mediante una fantasía que reagrupe los elementos del problema sin rebasar la extensión que cubren, y cuya exactitud se controla por la desaparición de la pregunta. (Adorno, 1931/1991a, p. 99)

Em curso sobre a dialética, Adorno (1958/2013) defende que essa expressa a contradição do objeto apreendida pelas categorias do sujeito; em "A educação contra a barbárie" (Adorno, 1968/1995c), define experiência pelo confronto entre sujeito e objeto. O sujeito nunca conseguirá delimitar plenamente o objeto, mas na distinção entre ambos se dá o conhecimento: retirando-se a moldura posta pelo sujeito, resta o objeto, mas como enfatizado antes, não é possível dissociá-los, de modo a chegar à percepção de um objeto puro, sem a intervenção de categorias humanas, tal qual Kant (1781/2001) pode expor em sua Crítica da razão pura. Não é outra, ao que parece, a relação que Horkheimer e Adorno (1947/1985) propõem existir entre projeção e controle da projeção como necessária para o conhecimento e a ruptura entre esses dois movimentos como expressão de falsas projeções e, portanto, de falsos conhecimentos: o objeto produzido por meras projeções é idealizado, propício à paranoia; o objeto reproduzido por categorias fixas do sujeito que não as reconhece como seu produto constitui a sombra da paranoia:

A tendência à falsa projeção é tão fatalmente inerente ao espírito que ela, esquema isolado da autoconservação, ameaça dominar tudo o que vai além dela: a cultura. A falsa projeção é o usurpador do reino da liberdade e da cultura; a paranoia é o sintoma do indivíduo semicultivado. Para ele, todas as palavras convertem-se num sistema alucinatório, na tentativa de tomar posse pelo espírito de tudo aquilo que em 
sua experiência não alcança, de dar arbitrariamente um sentido ao mundo que torna o homem sem sentido, mas ao mesmo tempo se transformam também na tentativa de difamar o espírito e a experiência de que está excluído e de imputar-lhes a culpa que, na verdade, é da sociedade que o excluí do espírito e da experiência. Uma semicultura que, por oposição à simples incultura, hipostasia o saber limitado como verdade não pode mais suportar a ruptura entre o interior e o exterior, o destino individual e a lei social, a manifestação e a essência. (p. 182)

As técnicas de experimentação são produtos históricos dos sujeitos, e, como defendem Horkheimer e Adorno (1956/1973a), devem ser escolhidas em função dos objetos, e não o contrário. Como a sociedade é contraditória, os objetos também apresentam contradições entre aparência e o que se move por trás dessa aparência. Essa aparência, tal como a ideologia, é socialmente necessária. Por vezes, a aparência está tão distante do que é essencial ao indivíduo que se contrapõe a ele, mas nem por isso lhe é exterior. Com métodos reconhecidos, Marx e Freud partem do aparente - o preço da mercadoria, para um, os atos falhos, os lapsos, a palavra, para o outro - para chegarem às bases sociais e psíquicas. A aparência não expressa diretamente a essência, mas mesmo quando lhe parece externa, tal como a publicidade em relação à mercadoria que trata, a revela por sua negação.

Há técnicas de pesquisa associadas à descrição da aparência e outras que visam a estudar o que ocultam e podem revelar. E aqui é necessário fazer a distinção entre o que é devido ao sujeito - a análise - e o que é próprio ao objeto - suas leis e características: uma análise da superfície não deveria ser superficial; uma análise do que está por trás da aparência, por outro lado, pode ser superficial. Tal como os artistas, os profissionais liberais, o pesquisador deve ter aprendido bem suas técnicas, e, se isso ocorreu, sua análise da superfície ou de suas determinações não diretamente detectáveis não será superficial, e, deve-se afirmar: ambos os níveis de análise são importantes.

Uma análise de opiniões, de atitudes, se bem feita, pode trazer conhecimentos ou suscitar hipóteses a serem aprofundadas, e como o aprofundamento nunca é pleno, sempre será necessário aprofundar mais. Uma ilustração disso é a análise feita pelos autores de $A$ personalidade autoritária (Adorno, Frenkel-Brunswik, Levinson, \& Sanford, 1950) sobre as correlações entre as escalas que mensuravam o preconceito e a escala que indicava a posição política dos sujeitos pesquisados. Analisaram dados de superfície, mas se sua análise fosse superficial teriam se satisfeito com a magnitude e a direção da correlação que encontraram, confirmando sua hipótese; como dominavam bem a análise estatística e, dentro dessa, a análise de dispersão dos dados, puderam apresentar considerações novas, tais como a de que nem todo conservador do ponto de vista político é preconceituoso, e nem todo liberal é isento de preconceitos.

Por outro lado, entrevistas e testes projetivos, que visam o aprofundamento do que está subjacente à superfície, podem, devido à coleta e análise de dados, gerar análises superficiais, quando o entrevistador não desenvolve um procedimento adequado e não tem uma teoria consistente que apoie essa análise.

A descrição de Adorno et al. (1950) dos tipos de personalidade autoritária só foi possível devido aos conhecimentos que tinham da psicanálise e de uma teoria que relacionava o particular com a totalidade social. Dessa análise, surgiu outra questão importante indicada por esses autores que ressaltam a distinção feita anteriormente entre a análise que é própria ao pesquisador e o que é pertencente ao próprio objeto: os indivíduos - o objeto analisado - têm se constituído de maneira tão precária que não é devido ao instrumento a sua redução à tipificação, uma vez que esses indivíduos já se encontram tipificados. É a teoria e o procedimento adequado de coleta dos dados, que depende dessa teoria, que permitem a análise não ser superficial, e não os instrumentos utilizados. A análise estatística de Durkheim (1897/2008) sobre o suicídio ainda hoje é válida, além de ter a virtude de não fazer mais uma vez a responsabilidade da violência recair sobre o indivíduo, ao considerar doente quem tentou ou conseguiu se matar.

\section{Relações entre teoria e empiria}

Se a teoria, como afirmado antes, diz respeito à descrição do movimento do objeto, de sua transformação e de suas potencialidades, ela não conhece todo desenvolvimento possível do objeto, mas somente os que já ocorreram. Assim, a não ser que se trate de uma teoria dogmática ou uma teoria tradicional, tal como delimitada por Horkheimer (1937/1983), não há como saber o que teorias elaboradas em outros tempos e lugares poderiam dizer sobre a constituição atual de determinados objetos. É certo que boas teorias analisam tendências, mas se a história é síntese de continuidade e de rupturas, essas tendências podem ser modificadas. Não há como saber, a não ser de modo precário, o que os autores da Teoria Crítica da Sociedade pensariam a respeito da educação inclusiva ou da internet, ainda que seja possível um pensamento arriscado sobre o quanto essas práticas seguem ou não suas análises e propostas. Se a teoria contém a história 
do objeto, ela não pode ser posta à prova pelos achados empíricos, a não ser que seja somente especulação; claro, a especulação é fundamental para a constituição de uma teoria, mas só ela não é suficiente.

Um texto como "Capitalismo tardio ou sociedade industrial", de Adorno (1968/2004a), que abre o congresso de mesmo nome na década de 1960, não desmente a teoria marxiana, antes mostra dados que atestam sua coerência. $\mathrm{O}$ fato de as forças produtivas não terem libertado as relações de produção, pois foram aprisionadas por essas últimas, indica uma alteração de direção e sentido que rompe com a continuidade do movimento e que implica a regressão social, à medida que o progresso ocorre. Assim, Adorno pode assinalar que o capitalismo ainda existe da forma descrita por Marx, mas com uma configuração distinta; essa nova configuração não expressa somente uma nova fachada, mas um novo modo de exploração.

Se o socialismo real ocorreu num país considerado atrasado do ponto de vista econômico, e esse dado mostra a falha de previsão marxiana, isso não implica que a teoria marxiana estava errada, mas que, como sabia seu autor, a história não é teleológica, possui múltipla determinação. Quando Adorno (1955/1991b) alega que a psicanálise é anacrônica, isso não implica que ela não analisou adequadamente o indivíduo que já deixava de ser possível, pois, justamente por isso, pode passar a ser medida da regressão psíquica.

São dados empíricos, cujas coleta e análise não são dissociadas da teoria, que permitem a essa teoria prosseguir em seu trabalho de descrição das transformações e potencialidades dos objetos; nesse sentido, serão apresentados, a seguir, alguns resultados de pesquisas realizadas no Laboratório de Estudos sobre o Preconceito do Instituto de Psicologia da USP; deve-se adiantar que, entre esses resultados, também foram encontrados alguns que não confirmam plenamente a teoria.

Um desses resultados se refere à relação entre tipo psicológico e adesão à ideologia, tal como foi estudada em A personalidade autoritária (Adorno et al., 1950). Se o tipo sadomasoquista era predominante na época desse estudo, Adorno (1955/1991b), mais à frente, indicou que a personalidade narcisista a estava substituindo como base da ideologia autoritária, conforme se pode concluir da citação abaixo:

La configuración de la energía pulsional en que se apoya el yo - según el tipo analítico freudiano cuando llega a dar el paso hasta el sumo sacrificio, el de la consciencia misma, es el narcisismo. Apuntan a él con una fuerza probatoria incontrovertible todos los hallazgos de la psicología social referentes a las regresiones predominantes en la actualidad, en las que el yo se niega y al mismo tiempo se endurece de una forma irracional y falsa. El narcisismo socializado que caracteriza los movimientos y actitudes de masa del más reciente estilo aúna sin contemplaciones la racionalidad parcial del interés propio con las deformaciones irracionales del tipo destructivo y autodestructivo cuya interpretación ha enlazado Freud con los hallazgos de Mac Dougall y Le Bon. (pp. 183184)

Uma nova ideologia também se configurou e tende a se relacionar com o narcisismo: a da racionalidade tecnológica, que consiste em perceber o mundo e seus problemas, assim como suas soluções, a partir de uma razão técnica, instrumental, que a tudo reduz a um sistema com uma lógica imanente, desconsiderando o que é próprio do que tem vida: conflitos e contradições. Essa ideologia foi apresentada, ainda que nem sempre nomeada, por Horkheimer e Adorno (1947/1985), em sua crítica ao Esclarecimento, por Marcuse (1964/1982), em sua análise do que nomeou de homem unidimensional, e por Habermas (1968/1983), quando analisou a ciência e a técnica como ideologia. A relação entre esse novo tipo predominante de personalidade - a narcisista - e essa nova ideologia - a da racionalidade tecnológica - foi verificada pelos estudos realizados por Crochík (2000, 2005).

Por meio de aplicação de escalas que avaliaram características narcisistas de personalidade, adesão à ideologia da racionalidade tecnológica, conservadorismo político-econômico e a escala F, elaborada por Adorno et al. (1950), em estudantes universitários, obtiveram-se correlações maiores entre os escores da Escala F com os da escala da adesão à Ideologia da racionalidade tecnológica e com os da Escala de Conservadorismo político-econômico do que as obtidas entre os escores da Escala de características narcisistas de Personalidade e essas duas últimas que avaliam adesão à ideologia. Todos os escores tenderam a se relacionar de forma significante entre si, e os escores da Escala de características narcisistas foram maiores do que os obtidos na Escala F. Assim, se os sujeitos pesquisados tinham mais traços narcisistas do que sadomasoquistas, estes últimos ainda estavam mais associados com a ideologia do que os primeiros. $\mathrm{O}$ narcisismo não substituiu o sadomasoquismo, tornou-se mais uma modalidade frequente de regressão psíquica; para sustentar a ideologia da sociedade administrada, no entanto, os traços sadomasoquistas ainda são mais importantes. Esse resultado não torna falsa a tendência prevista pelos frankfurtianos, mas permite vislumbrar que direção está seguindo, preservando ainda o que supostamente havia sido superado: o tipo de personalidade sadomasoquista, 
a ideologia conservadora e sua relação, ainda que o indivíduo que tenha características narcisistas também tenda a aderir a essa ideologia em menor grau. Essa informação é relevante pois, além de se ter de preocupar com as novas formas de regressão psíquica e com ideologias que se relacionam a elas, não se pode descuidar das anteriores.

Outro dado empírico obtido recentemente permitiu repensar uma análise importante de Adorno $(1965 / 1995 b)$. Se esse autor argumentou que, no fascismo, a hierarquia escolar não-oficial era jogada contra a hierarquia oficial, Crochík (2016) encontrou dados que não confirmaram plenamente essa afirmação. Mediante escalas que avaliaram a posição de colegas do ensino fundamental II na hierarquia escolar considerada oficial - a referente ao desempenho nas diversas disciplinas ministradas em sala de aula - e na hierarquia não-oficial - que se refere ao desempenho na disciplina de Educação Física e à popularidade - e escalas que pediam a indicação dos alunos que mais praticavam e dos que mais sofriam agressões próprias ao bullying, verificou-se, em estudantes desse nível de ensino, que os estudantes classificados na base das duas hierarquias tendem a ser molestados, e os que se encontram no ápice de cada uma delas, não. Estes últimos se diferenciam ao participar ou não da violência escolar entre os estudantes: os alunos que se saem bem nas disciplinas escolares tendem a não ser alvos nem autores de agressão; os que se destacam na hierarquia não-oficial tendem a praticar diversas formas de agressão contra os colegas. Esse resultado indica mudanças em relação aos alunos que são considerados com destaque quanto a seu desempenho escolar, que parecem formar, na classe, um grupo à parte; talvez isso se deva pela clara demonstração que pessoas com boa escolarização possam ter melhores ocupações e remuneração nessas ocupações e serem pessoas que obtiveram sucesso, um sinal de força talvez admirado pelos colegas que se sobressaem na outra hierarquia, ainda que os primeiros não tendam a agredir os que têm um mau desempenho escolar. Não se trata, ou não se trata mais, de uma hierarquia que é lançada contra a outra, mas daqueles que se destacam na hierarquia não-oficial agredirem os que têm mau desempenho em ambas hierarquias; mais do que antes, o que se valoriza é se destacar nas hierarquias, quaisquer que sejam elas.

Foi possível também, na pesquisa acima referida (Crochick \& Crochick, 2017), diferençar preconceito de bullying, entendendo que o primeiro possui um objeto melhor elaborado, ainda que fruto de idealização, ao passo que o último não precisa, necessariamente, de um objeto em especial para expressar seu desejo de dominação. Foi possível pensar que, no preconceito, é projetado sobre o alvo o que não se suporta em si mesmo, enquanto no bullying o que está presente é o puro desejo de subjugação do outro, não importa quem. Ora, se há essa distinção entre ambas as formas de violência, ainda que, por vezes, seja difícil separá-las, e se Horkheimer e Adorno (1947/1985) sustentaram que o principal entrave ao movimento do esclarecimento é a necessidade da dominação, já anacrônica do ponto de vista objetivo, então o que se apresentava como constituição subjetiva no fascismo alemão era o que subjaz ao bullying - a necessidade de subjugação -, e não o que é propício ao preconceito - a dificuldade de identificação -, recordando que a determinação fundamental para o surgimento e manifestação do fascismo é objetiva, isto é, social; os fatores subjetivos podem contribuir com a manutenção desse sistema, mas não gerá-lo.

Se Horkheimer e Adorno (1947/1985) enunciam no início do sétimo elemento do antissemitismo que não há mais antissemitas (deve-se lembrar que o livro foi publicado em meados da década de 1940), e, em um dos primeiros elementos, caracterizam o fascista como um sujeito sem subjetividade, então não se trata, nessa análise, do preconceito, mas de uma fúria sem destino, manobrada pela ordem social, que indica quais alvos podem ser atingidos - judeus, negros, ciganos, pessoas com deficiência. Se é assim, o que foi pesquisado em "A personalidade autoritária" não é o mesmo fenômeno estudado nos "Elementos do antissemitismo". Puderam detectar nos EUA o autoritarismo próprio ao preconceito, a hierarquia bem estabelecida, na qual cada um deve ocupar seu lugar e almejar o lugar do que está acima; na Alemanha nazista, não é uma hierarquia organizada que se apresenta, mas o desespero de o mundo não precisar mais de hierarquias o que suscita o desejo de dominação como movimento compensatório e regressivo.

De fato, Horkheimer e Adorno (1947/1985) não nomeiam o antissemitismo de movimento preconceituoso, e o texto sobre os "Elementos do Antissemitismo" é pouco citado no estudo pouco posterior sobre a personalidade autoritária, e, como salientado, os dados empíricos obtidos na pesquisa acima descrita (Crochík, 2016) sustentam essa distinção, visível somente no início do sétimo elemento do antissemitismo, para o qual os elementos destacados ao longo do texto já são somente sua base de sustentação, ou melhor, de sustentação da mentalidade do ticket:

Por isso, não desapareceram com o indivíduo seus determinantes psicológicos que sempre foram os agentes intra-humanos da falsa sociedade. Mas os tipos caractereológicos encontram agora seu lugar preciso no organograma da empresa de poder. Seus 
coeficientes de rendimento e de atrito estão incluídos no cálculo. O próprio ticket é uma roda da engrenagem. Tudo o que, no mecanismo psicológico, foi sempre compulsivo, sem liberdade e irracional está adaptado a isso de uma maneira precisa. O ticket reacionário que contém o antissemitismo é adequado à síndrome destrutivo-convencional. Originariamente, eles representam menos uma reação contra os judeus de que a formação de uma orientação pulsional à qual só o ticket fornece um objeto adequado de perseguição. Os "elementos do antissemitismo", baseados na experiência e anulados pela perda da experiência que se anuncia na mentalidade do ticket, são novamente mobilizados pelo ticket. Já tendo entrado em decomposição, eles trazem para o neo-antissemita a má consciência e, com ela, a insaciabilidade do mal. (Horkheimer e Adorno, 1947/1985, p. 192)

A perda da experiência, e assim do indivíduo, o levam à regressão própria à síndrome destrutivaconvencional, que certamente também caracteriza alguns dos tipos de personalidade autoritária descritos por Adorno, mas esses talvez não devessem ser denominados de preconceituosos, como Horkheimer e Adorno (1956/1973b) o fazem em um texto síntese nomeado de "Preconceito'. O que subjaz ao bullying, ao que parece, é uma regressão ainda maior do que a presente no preconceito, e, assim, quer na época dos estudos em questão - década de 1940 -, quer atualmente, existem indivíduos não preconceituosos, provavelmente em pouca frequência, os que são preconceituosos, que tiveram seu desenvolvimento psíquico paralisado, e os que quase não se desenvolvem, os que seriam propícios à pura dominação, sem nenhuma necessidade de especificação do alvo a ser agredido.

Essa análise, se for correta, permite entender por que o preconceito depende e independe do objeto contra o qual se dirige, tal como formulado em outro texto (Crochík, 2011), com base nos estudos dos frankfurtianos: depende para um indivíduo mais desenvolvido, ainda que não adequadamente; independe para um indivíduo que quase não distingue a si mesmo dos outros, a não ser como possibilidade de suas próprias satisfações. Também permite entender por que o indivíduo que tem preconceito contra um alvo também o tem em relação a outros alvos: para uns, diversos alvos podem assumir desejos especificamente negados, relacionados entre si; para outros, a própria fragilidade se converte em motivo de agressão. De todo modo, os dados desse estudo indicam que há formas distintas de violência presentes na sociedade que cabe não confundir, mesmo porque necessitam de formas diversas para serem enfrentadas.

\section{Considerações finais}

Adisciplina psicologia social parece ser adequada para estudar a regressão psíquica contemporânea, não como complemento da psicologia, mas como seu prosseguimento; a fragilidade atual do indivíduo expressa a dificuldade que algo propriamente psicológico se estabeleça, se estruture. A teoria social que pode prever essa tendência se calca na empiria, e dentro dessa em estudos experimentais, que não podem invalidar a teoria, mas indicar transformações de seus objetos que devem ser pensados teoricamente como história do objeto e, portanto, história social.

É verdade que alguns dos dados aqui apresentados ainda estão em análise, mas são suficientes para ilustrar a relação entre teoria e empiria tal como foi apresentada. Não é uma relação direta, nem imediata; uma - a teoria - tem a história como descrição do movimento do objeto, a outra - a empiria -, a história condensada no objeto. Se a pesquisa empírica não trouxesse dados que permitissem pensar a atualidade dos conceitos teóricos não seria necessária, e a teoria seria dogmática; sem a teoria, os dados ocultam a determinação que os constitui.

Os resultados apresentados são provenientes de medidas consideradas de superfície, tal como mencionadas na segunda parte deste trabalho, com exceção da Escala F, que se propõe avaliar características profundas de personalidade, mas permitem análises, cujas interpretações teóricas possibilitam aprofundar a compreensão dos objetos estudados,

De acordo com esses resultados, há tipos de personalidades ditas anacrônicas que convivem com as esperadas; ideologias superadas que insistem em sobreviver, também em função de sua racionalidade, quando existe; alguns tipos de personalidade se associam mais com determinadas ideologias do que outras, mas convivem como fragmentos, mediados pela mesma totalidade; é o estudo desses fragmentos que permite o conhecimento da totalidade e, assim, do que a constitui; mas, para esse conhecimento, as pesquisas empíricas são fundamentais.

Por fim, cabe destacar que se a Teoria Crítica não é nem filosofia, nem sociologia, nem psicanálise, nem estética, ela não implica, como defendia Horkheimer, a interdisciplinaridade, uma vez que esta última é lógica do sujeito, e o que se busca com a teoria e com a empiria é a descrição do objeto; esse objeto pode ser mais bem aprendido pelo especialista do que pelo que é detentor de múltiplos saberes e de nenhum em particular. Essa crítica reverbera mais 
uma vez o primado do objeto que não se obtém pelo saber múltiplo, mas pela articulação de vários saberes independentes suscitados pelo objeto.

\section{Referências}

Adorno,T. W. (1969). Opinión, Locura, Sociedad. In Intervenciones: nueve modelos de critica (pp.137-160). Caracas: Monte Ávila.

Adorno, T. W. (1991a). Actualidad de la filosofia. In T.W. Adorno, Actualidade de la filosofia (pp.73-102). Barcelona: Paidós. (Original publicado em 1931)

Adorno, T. W. (1991b). De la relación entre sociología y psicología. In Actualidad de la filosofia (J. L. A. Tamayo, Trad., pp. 135-204). Barcelona: Paidós. (Original publicado em 1955)

Adorno, T. W. (1995a). Educação e emancipação. Rio de Janeiro: Paz e Terra. (Original publicado em 1970)

Adorno, T. W. (1995b). Tabus acerca do magistério. In Educação e emancipação (pp. 97-117). Rio de Janeiro: Paz e Terra. (Original publicado em 1965)

Adorno, T. W. (1995c). A educação contra a barbárie. In Educação e emancipação (pp.155-168). Rio de Janeiro: Paz e Terra. (Original publicado em 1968)

Adorno, T. W. (2004a). Capitalismo tardío o sociedad industrial? In Escritos sociológicos I (pp. 330-344). Madrid: Ediciones Akal. (Original publicado em 1942)

Adorno, T. W. (2004b). Tesis sobre la necesidad. In Escritos sociológicos I (pp. 365-368) Madrid: Ediciones Akal. (Original publicado em 1942)

Adorno, T. W. (2008). Introdução à sociología. São Paulo: Editora UNESP.

Adorno, T. W. (2013). Introducción a la dialéctica. Buenos Aires: Eterna Cadência. (Original publicado em 1958)

Adorno, T. W. (2015). Pós-escrito. In Ensaios sobre psicologia social e psicanálise (pp. 127-135). São Paulo: Editora UNESP. (Original publicado em 1966)

Adorno, T. W., Frenkel-Brunswik, E., Levinson, D. J., \& Sanford, R. N. (1950). The authoritarian personality. New York: Harper and Row.

Crochík, J. L. (2000). Tecnologia e individualismo: um estudo de uma das relações contemporâneas entre ideologia e personalidade. Análise Psicológica (Portugal), 4(18), 529543.

Crochík, J. L. (2005). Preconceito: relações com a ideologia e com a personalidade. Estudos de Psicologia, 22(3), 309-319.

Crochík, J. L. (2011). Preconceito, indivíduo e cultura ( $3^{\mathrm{a}} \mathrm{ed}$.). São Paulo: Casa do Psicólogo.

Crochík, J. L. (2016). Hierarchy, Violence and Bullying Among Students of Public Middle Schools. Paidéia, 26(65), 307315.

Crochick, J. L. \& Crochick, N. (2017). Bullying, Prejudice and School Performance: a New Approach (1a ed.). Springer International Publishing (Verlag)

Durkheim, E. (2008). O suicídio. São Paulo: Martin Claret. (Original publicado em 1897)

Freud, S. (1993). Psicologia de las masas y análisis del yo. In Obras completas (Vol. XVIII, pp. 63-136). Buenos Aires: Amorrortu (Original Publicado em 1921)

Habermas, J. (1983). Técnica e ciência enquanto ideologia. In Textos escolhidos: Benjamin, Horkheimer, Adorno, \& Habermas (pp. 313-343). São Paulo: Abril Cultural.
(Original publicado em 1968)

Horkheimer, M. (1983). Teoria Tradicional e Teoria Crítica. In Textos escolhidos: Benjamin, Horkheimer, Adorno, Habermas (pp. 117-154). São Paulo: Abril Cultural. (Original publicado em 1937)

Horkheimer, M. \& Adorno, T. W. (1973a). Sociologia e investigação social empírica. In Temas básicos da sociologia (pp. 120-131). Rio de Janeiro: Zahar. (Original publicado em 1956)

Horkheimer, M. \& Adorno, T. W. (1973b). Preconceito. In Temas básicos da sociologia (pp. 172-183). Rio de Janeiro: Zahar. (Original publicado em 1956)

Horkheimer, M. \& Adorno, T. W. (1973c). Ideologia. In Temas básicos da sociologia (pp. 184-205). Rio de Janeiro: Zahar. (Original publicado em 1956)

Horkheimer, M. \& Adorno, T. W. (1985). Dialética do esclarecimento. Rio de Janeiro: Zahar. (Original publicado em 1947)

Kant. I. (2001). Crítica da razão pura (5a ed.). Lisboa: Fundação Calouste Gulbenkian. (Original publicado em 1781)

Laplanche, J. \& Pontalis, J-B. (1988). Vocabulário da psicanálise. São Paulo: Martins Fontes.

Marcuse, H. (1982). A ideologia da sociedade industrial (G. Rebuá, Trad.). Rio de Janeiro: Zahar. (Obra original publicada em 1964).

Marx, K. (1978). Manuscritos econômicos-filosóficos. In Manuscritos econômicos-filosóficos e outros textos escolhidos (pp. 03-48). São Paulo: Abril Cultural. (Original publicado em 1844)

Agência de fomento: $\mathrm{CNPq}$ - Bolsa Produtividade em Pesquisa. No. do processo 306038/2014-5

Submissão em: 11/01/2017

Aceite em: 21/07/2017

José Leon Crochick é professor titular do Instituto de Psicologia da USP. Bolsista Produtividade em Pesquisa do CNPq.

Endereço: Departamento de Psicologia da Aprendizagem, do Desenvolvimento e da Personalidade. Instituto de Psicologia da USP. Av. Professor Mello de Morais, 1721. Butantã. São Paulo/SP, CEP 05508-030. E-mail: jlchna@usp.br 